\title{
Health care utilization and cost associated with switching biologics within the first year of biologic treatment initiation among patients with ankylosing spondylitis
}

Esther Yi, PharmD; Dong Dai, PhD; Olivia W Piao, MS; Josh Z Zheng, MS; Yujin Park, PharmD

\section{What is already known about this subject}

- Currently, the available biologics approved for the treatment of ankylosing spondylitis (AS) in the United States include tumor necrosis factor inhibitors (adalimumab, certolizumab pegol, etanercept, and golimumab) and interleukin-17A inhibitors (ixekizumab and secukinumab)

- Patients may discontinue or switch biologic therapies in clinical practice due to adverse events, lack of efficacy, or formulary changes.

- A few studies have retrospectively identified treatment patterns in patients with AS, but there is limited real-world evidence comparing health care costs and resource utilization associated with switching or discontinuing between approved biologics.

\section{ABSTRACT}

BACKGROUND: Costs associated with biologic switching and discontinuation can be high in chronic inflammatory diseases. Inappropriate use of medications may have cost implications for both payers and patients. Understanding of biologic utilization and switching rates is lacking among patients with ankylosing spondylitis (AS).

OBJECTIVE: To compare direct costs of treatment switchers, nonswitchers, and discontinuers among patients with AS who newly initiated a biologic.

\section{What this study adds}

- This retrospective analysis of U.S. administrative claims data shows that within 1 year of initiating a biologic (adalimumab, certolizumab pegol, etanercept, golimumab, or secukinumab), $53.1 \%$ of patients with AS remained on their index biologic; $15.4 \%$ switched from their index biologic to a new therapy; and $31.5 \%$ discontinued their index biologic.

- Switchers and discontinuers had higher health care resource utilization (emergency and outpatient visits) than nonswitchers.

- Switchers had the highest total health care costs, which were driven by increased pharmacy and medical costs, while discontinuers had the lowest total health care costs due to decreased pharmacy costs from early discontinuation of medications but also had the highest medical costs.

METHODS: Patients aged $\geq 18$ years with an AS diagnosis and $\geq 1$ pharmacy claim for an FDA-approved subcutaneous biologic for AS between January 1, 2016, and December 31, 2016 (identification period) were identified from the Truven Health MarketScan Databases. At the time of biologic initiation (index date), eligible patients were continuously enrolled with medical and pharmacy claims for $\geq 1$ year before (baseline period) and $\geq 1$ year after the index date (follow-up period). Patients with AS were categorized into 3 mutually exclusive groups of nonswitchers (patients who remained on their index biologic), switchers (patients who had

\section{Author affiliations \\ Esther Yi, PharmD; Dong Dai, PhD; and Yujin Park, PharmD, Novartis Pharmaceuticals Corporation, East Hanover, NJ. Olivia W Piao, MS, and Josh Z Zheng, MS, KMK Consulting, East Hanover, NJ.}

\section{AUTHOR CORRESPONDENCE:}

Esther Yi, 862.337.0359;

esther.yi@novartis.com

J Manag Care Spec Pharm 2021;27(1):27-36

Copyright $\odot 2021$, Academy of Managed Care Pharmacy. All rights reserved.

a prescription for a biologic therapy other than their index biologic), and discontinuers (patients who had gaps in prescription claims [>120 days]) based on their biologic utilization pattern during the 1-year followup period. Health care costs (inflated to year 2017 costs) during follow-up were described across the 3 groups separately and by disease. Adjusted health care resource utilization and costs during 1-year follow-up were estimated, controlling for age, sex, fulltime work status, and Charlson Comorbidity Index (Deyo's modification) during the baseline period. 
RESULTS: A total of 791 patients with AS who were newly initiating a biologic were categorized as switchers (15.4\%), nonswitchers (53.1\%), and discontinuers (31.5\%). Switchers and discontinuers had higher all-cause health care utilization than nonswitchers during the 1-year follow-up period. Switchers had higher mean total health care costs than nonswitchers $(\$ 71,280$ vs. $\$ 66,573)$ due to increased medical $(\$ 13,897$ vs. $\$ 12,043)$ and pharmacy costs $(\$ 57,384$ vs. $\$ 54,530)$. Discontinuers had the lowest total health care costs $(\$ 41,179)$ but had the highest medical costs $(\$ 19,079)$. Adjusted analyses for covariates confirmed similar trends as the unadjusted analysis, where discontinuers had significantly lower total health care and pharmacy costs but had higher medical costs (with increased emergency department and outpatient visits) than nonswitchers (all $P<0.001$ ). Switchers had increased outpatient visits and costs versus nonswitchers in the adjusted analysis $(P<0.001)$; small sample sizes in the switcher group may have limited the ability to detect significant trends in the adjusted analysis.

CONCLUSIONS: Biologic switching resulted in higher total health care costs than remaining on the same biologic in patients with AS. These findings highlight the clinical and economic impact of discontinuing or switching biologic therapies in patients with AS, which may inform treatment and/or formulary decision making.

Ankylosing spondylitis (AS) is a chronic, immune-mediated rheumatic disease that primarily affects the spine and manifests as progressive spinal stiffness and fusion. ${ }^{1}$ The main clinical feature of AS is inflammatory back pain, which is caused by inflammation of the vertebrae and joints of the spine and entheses. ${ }^{1,2}$ The prevalence of AS is estimated at $0.35 \%$ to $0.67 \%$ in the United States..$^{1,3-6}$ However, given that AS is often underdiagnosed or diagnosed late, ${ }^{7}$ some believe it may actually affect approximately $1 \%$ in the United States. ${ }^{3}$ The usual age of symptom onset is $15-35$ years, with a delay in diagnosis of up to 14 years..$^{89}$ Factors that likely contribute to delayed diagnosis of AS include the broad prevalence of chronic lower back pain in the population (including mechanical back pain), gradual onset of the disease, and lack of specific symptoms or biomarkers unique to AS. ${ }^{9}$ Several lines of evidence suggest that severe deformities, disabilities, and functional limitations often develop within the first 10 years of AS. ${ }^{10,11}$

Along with severely affecting physical function, AS poses a substantial economic burden to patients, payers, and society due not only to health care utilization and costs related to delayed diagnosis but also to lifelong, continuous treatment. ${ }^{12,13}$ In a study of U.S. administrative claims data, patients with AS had approximately 4-fold higher mean total all-cause health care costs than a matched control population without AS $(\$ 33,285$ vs. $\$ 8,310$ per patient per year), driven by increased use of medical outpatient services (i.e., emergency department [ED] visits, nonhospital-based outpatient visits, hospital-based outpatient visits, and other outpatient services) and pharmacy costs (all $\mathrm{P}<0.05) .{ }^{12}$ The majority of AS-specific total health care costs were related to AS medication costs. In a systematic review of the indirect costs relating to work absenteeism and presenteeism associated with AS, the mean annual indirect cost was $\$ 6,455$ per patient per year, with a range of $\$ 661$ to $\$ 45,954$ depending on the components of indirect costs and their definitions..$^{14}$ Other studies, mostly from outside the United States, have found that indirect health care costs associated with AS were higher than direct costs. ${ }^{15}$

The Assessment of SpondyloArthritis international Society (ASAS), the European League Against Rheumatism (EULAR), the American College of Rheumatology (ACR)/ Spondylitis Association of America (SAA), and the Spondyloarthritis Research and Treatment Network (SPARTAN) all recommend nonsteroidal anti-inflammatory drugs (NSAIDs) as first-line therapy in patients with active disease who have pain and stiffness; in patients with active disease despite NSAID treatment, use of biologic therapy is recommended. ${ }^{16,17}$ Biologic therapies approved for the treatment of AS include the tumor necrosis factor inhibitors (TNFis) adalimumab, etanercept, certolizumab pegol, and golimumab and the interleukin (IL)-17A inhibitors secukinumab and ixekizumab. ${ }^{18-26}$ Current practice suggests the use of a TNFi as first-line biologic therapy. ${ }^{16}$ The 2019 update of the ACR/SAA/SPARTAN guidelines for the treatment of AS and nonradiographic axial spondyloarthritis conditionally recommends IL-17 inhibitors over treatment with a different TNFi among primary nonresponders to TNFis and treatment with a second TNFi over a non-TNFi biologic if the initial TNFi loses efficacy over time. ${ }^{17}$ Lack of primary response or loss of effectiveness over time is a common reason for biologic switching. ${ }^{27}$ Previous studies have also shown that switching biologics may be effective if the initial biologic fails ${ }^{28,29}$; however, switching biologics may lead to increased health care utilization. Adherence to and persistence with biologic therapy in patients with AS is vital to achieve optimal outcomes of pain relief, improved physical function, and minimal joint damage. ${ }^{30}$ Therefore, appropriate selection of medications is important for optimizing patient outcomes and minimizing costs.

Because of the array of biologic treatment options, it is important to assess the cost of switching or discontinuing biologics among patients with AS. Previous retrospective studies have predominantly focused on treatment patterns and costs of TNFis. ${ }^{31,32}$ Therefore, there is a need for more studies evaluating the real-world health care costs and utilization associated with newer biologic treatments for 
AS. This study aimed to compare health care utilization and costs of switching and discontinuing biologics versus remaining on index biologic during 1 year of follow-up among patients with AS.

\section{Methods}

\section{STUDY DESIGN AND PATIENT POPULATION}

A retrospective, observational cohort study was conducted using the Truven Analytics MarketScan Commercial Claims and Encounters Database (CCAE) and the Medicare Supplemental and Coordination of Benefits Database (MDCR) from January 1, 2015, to December 31, 2017. The Truven Analytics MarketScan data source is widely used for analyzing epidemiologic and economic outcomes in the U.S. health care system. CCAE contains administrative claims data from a privately insured population, while the MDCR contains administrative claims data from retirees with Medicare supplemental insurance paid by employers, employer-paid portion, services provided under Medicare-covered payment, and any out-of-pocket expenses. The CCAE and MDCR include fully adjudicated deidentified medical claims, outpatient prescription drug claims, and person-level enrollment data that are linked with unique patient identifiers. Demographic variables (age, gender, employment status, insurance plan type, and geographic location) and detailed health care costs and utilization for health care services performed in both inpatient and outpatient settings are captured.

Patients aged $\geq 18$ years with $\geq 1$ pharmacy claim for a subcutaneously administered biologic that was approved by the U.S. Food and Drug Administration for AS by 2017 (adalimumab, etanercept, certolizumab pegol, golimumab, and secukinumab) from January 1, 2016, to December 31, 2016 (identification period), were identified in the Truven Health Analytics MarketScan Commercial and Medicare Supplemental Databases. Eligible patients at the time of biologic initiation (index date) were continuously enrolled, had medical and pharmacy claims for $\geq 1$ year before (baseline period) and $\geq 1$ year after the index date (follow-up period), and had $\geq 1$ AS diagnosis (International Classification of Diseases, Ninth Revision, Clinical Modification [ICD-9-CM] 720.0 and Tenth Revision [ICD-10-CM] M45.x) during the baseline period. Patients who had $>1$ different biologic of interest at the index date were excluded. The treatment washout period of 1 year allowed for a reduction in bias introduced by prevalent biologic use.

Use of the above study databases for health services research complies with the Health Insurance Portability and Accountability Act (HIPAA) and federal guidance on Public Welfare and the Protection of Human Subjects.

\section{STUDY VARIABLES}

Patients were categorized into 3 mutually exclusive groups based on their biologic treatment pattern groups during the 1-year follow-up period.

- Nonswitchers: Patients who remained on the index biologic with no gaps in treatment (>120 days) and no other claims for biologic therapies during the 1-year follow-up period

- Switchers: Patients who had a prescription claim for a different biologic therapy (adalimumab, certolizumab pegol, etanercept, golimumab, secukinumab) than the index biologic and who switched therapies before permissible treatment gaps (>120 days) were reached during the 1-year follow-up period

- Discontinuers: Patients who had prescription claim gaps (time from exhaustion of previous days supply) during the 1-year follow-up period (gap >120 days)

Patient demographics (age, sex, employment status, insurance plan type, and geographic location) were assessed at the index date; all-cause health care resource utilization (hospitalizations, ED visits, and outpatient visits) and all-cause health care costs (including medical [inpatient, outpatient, and ED costs] and pharmacy costs) were measured both during the 1-year baseline period and the 1-year follow-up period. All-cause health care resource utilization and health care costs were calculated per patient per year; health care costs were inflated to year 2017 costs.

\section{DATA ANALYSIS}

Descriptive statistics were tabulated for patient characteristics and outcome variables (health care resource utilization and costs) comparing nonswitchers versus switchers and nonswitchers versus discontinuers. Continuous variables were summarized as means and standard deviations, while categorical variables were presented as counts and percentages, with missing data considered a separate category. Comparisons between treatment pattern groups were made using $\chi^{2}$ tests for categorical variables and Wilcoxon rank-sum tests or unequal variance 2 -sample t-tests for continuous variables.

Multivariable models were fitted to compare all-cause health care resource utilization and costs between switchers versus nonswitchers and discontinuers versus nonswitchers using a negative binomial distribution with log link function for all outcomes. Adjusted health care utilization and costs were estimated for nonswitchers, switchers, and 


\section{FIGURE 1 Patient Selection and Attrition ${ }^{\mathrm{a}}$}

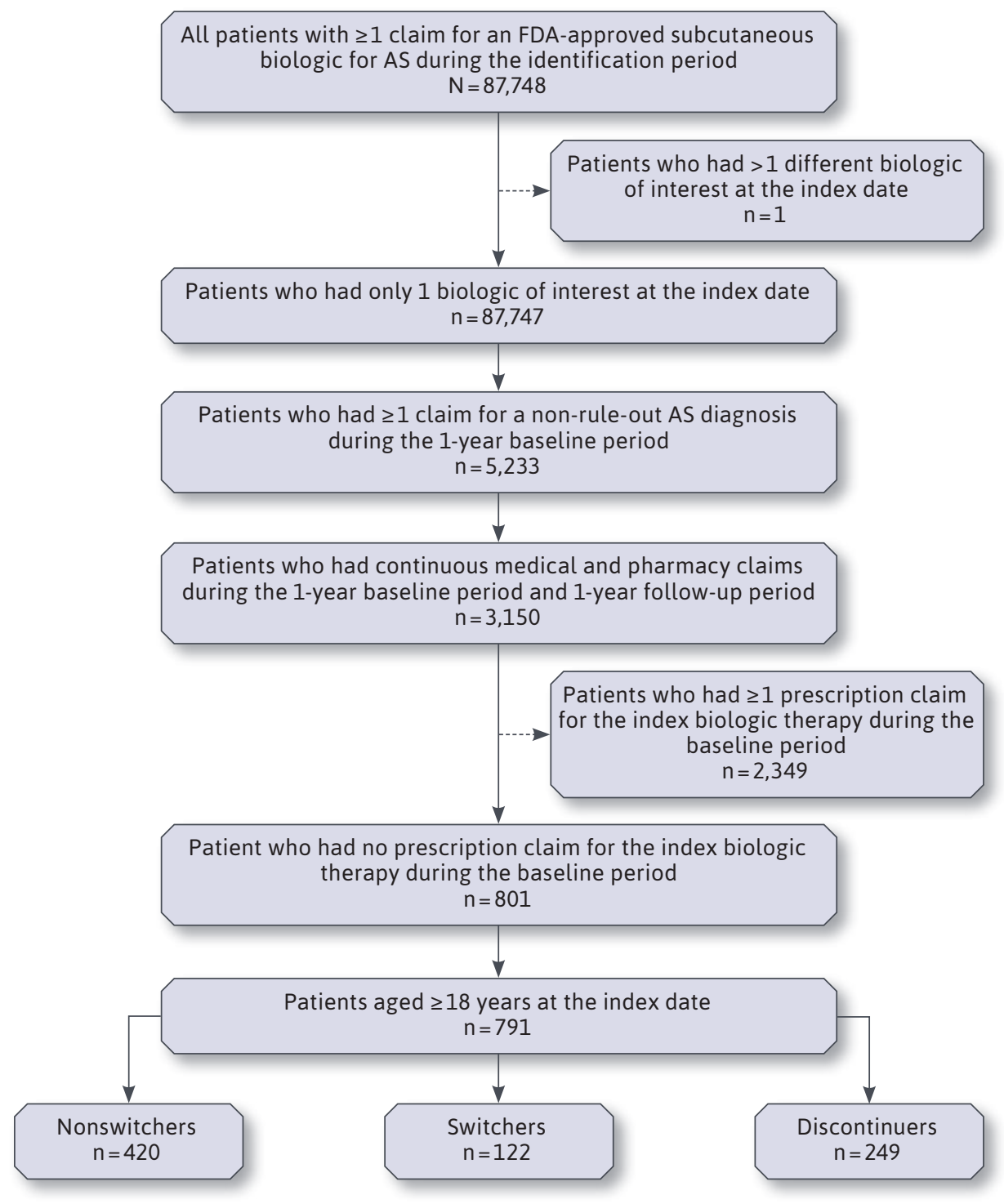

${ }^{a}$ Dashed lines represent exclusion criteria.

$A S=$ ankylosing spondylitis; FDA =U.S. Food and Drug Administration.

discontinuers based on the models. All models were adjusted to control for baseline covariates, including age, sex, full-time work status (yes or no), and baseline Charlson Comorbidity Index (Deyo's modification). All analyses were done using SAS software version 9.4 (SAS Institute, Cary, NC) in the EVICO platform. and December 31, 2016 (Figure 1). After inclusion and exclusion criteria were applied, the final study cohort consisted of 791 patients with AS who initiated a biologic; $15.4 \%$ were categorized as switchers, $53.1 \%$ as nonswitchers, and $31.5 \%$ as discontinuers. Overall, 404 patients (51.1\%) initiated adalimumab, 63 (8.0\%) initiated certolizumab pegol, 211 (26.7\%) initiated etanercept, 44 (5.6\%) initiated golimumab, and 69 (8.7\%) initiated secukinumab.

Patient demographics were mostly similar across treatment groups regarding age and employment status. Overall, the mean (SD) age was 46.5 (12.4) years, $51.2 \%$ were female, and most were from the southern region of the United States (44.2\%) (Table 1). The proportion of women among switchers was higher than that in nonswitchers $(63.1 \%$ vs. $46.4 \%$; $\mathrm{P}<0.05)$.

\section{BASELINE ALL-CAUSE HEALTH CARE RESOURCE UTILIZATION AND COSTS}

Across all treatment groups, the mean (SD) number of patient visits per year was 0.13 (0.42) for hospitalizations, 0.51 (1.19) for ED visits, and 31.31 (22.69) for outpatient visits (Table 2). Switchers had a significantly higher mean (SD) number of outpatient visits per patient per year than nonswitchers (36.35 [23.44] vs. 29.29 [21.70]; $P<0.001$ ). Both switchers and discontinuers had significantly higher mean (SD) number of ED visits per patient per year compared with nonswitchers (0.54 [0.93] and 0.63 [1.33] vs. 0.43 [1.17]; $P=0.031$ and $\mathrm{P}=0.026$, respectively).

At baseline, the overall mean (SD) total all-cause health care cost across all treatment pattern groups was $\$ 25,679$ (\$35,255), and medical and pharmacy costs were significantly different between switchers and nonswitchers (Table 2). Switchers 


\begin{tabular}{|c|c|c|c|c|}
\hline Characteristic & $\begin{array}{l}\text { Overall } \\
\mathrm{N}=791\end{array}$ & $\begin{array}{c}\text { Nonswitchers } \\
n=420\end{array}$ & $\begin{array}{c}\text { Switchers } \\
\mathrm{n}=122\end{array}$ & $\begin{array}{c}\begin{array}{c}\text { Discontinuers } \\
\mathrm{n}=249\end{array} \\
\end{array}$ \\
\hline Age, mean (SD), years & $46.5(12.4)$ & $46.4(12.3)$ & $48.7(11.8)$ & $45.5(12.7)$ \\
\hline Female, $n(\%)$ & $405(51.2)$ & $195(46.4)$ & $77(63.1)^{\mathrm{a}}$ & $133(53.4)$ \\
\hline \multicolumn{5}{|l|}{ Insurance plan type, n (\%) } \\
\hline Fee for service & $710(89.8)$ & 385 (91.7) & $100(82.0)^{\mathrm{a}}$ & $225(90.4)$ \\
\hline HMO and POS capitation & $72 \quad(9.1)$ & $33 \quad(7.9)$ & $17(13.9)^{\mathrm{a}}$ & $22(8.8)$ \\
\hline Unknown & $9 \quad(1.1)$ & $2(0.5)$ & $5 \quad(4.1)^{\mathrm{a}}$ & $2 \quad(0.8)$ \\
\hline \multicolumn{5}{|l|}{ U.S. region, $n$ (\%) } \\
\hline South & $350(44.2)$ & $184(43.8)$ & $66(54.1)^{\mathrm{a}}$ & $100(40.2)$ \\
\hline North central & 141 (17.8) & $89(21.2)$ & $13(10.7)^{\mathrm{a}}$ & 39 (15.7) \\
\hline Northeast & 135 (17.1) & $67(16.0)$ & $14(11.5)^{\mathrm{a}}$ & $54(21.7)$ \\
\hline West & $163(20.6)$ & $79(18.8)$ & $29(23.8)^{\mathrm{a}}$ & $55(22.1)$ \\
\hline Unknown & $2 \quad(0.3)$ & $1 \quad(0.2)$ & $0^{\mathrm{a}}$ & $1 \quad(0.4)$ \\
\hline \multicolumn{5}{|l|}{ Employment status, n (\%) } \\
\hline Active full time & $553(69.9)$ & $305(72.6)$ & $79(64.8)$ & $169(67.9)$ \\
\hline Active part time or seasonal & $10 \quad(1.3)$ & $5 \quad(1.2)$ & $1 \quad(0.8)$ & $4 \quad(1.6)$ \\
\hline Early retiree & $40 \quad(5.1)$ & $14 \quad(3.3)$ & $9 \quad(7.4)$ & $17 \quad(6.8)$ \\
\hline Medicare-eligible retiree & $30 \quad(3.8)$ & $16 \quad(3.8)$ & 2 (1.6) & $12 \quad(4.8)$ \\
\hline Retiree (status unknown) & 0 & 0 & 0 & 0 \\
\hline COBRA continuee & $1 \quad(0.1)$ & $1 \quad(0.2)$ & 0 & 0 \\
\hline Long-term disability & $6 \quad(0.8)$ & $2(0.5)$ & $1 \quad(0.8)$ & $3 \quad(1.2)$ \\
\hline Surviving spouse/dependent & $4 \quad(0.5)$ & $1 \quad(0.2)$ & $1 \quad(0.8)$ & $2 \quad(0.8)$ \\
\hline Other/unknown & $147(18.6)$ & $76(18.1)$ & $29(23.8)$ & $42(16.9)$ \\
\hline
\end{tabular}

had significantly higher mean (SD) all-cause total health care costs than nonswitchers $(\$ 35,968[\$ 47,220]$ vs. $\$ 23,893 \quad[\$ 34,503] ; \quad P<0.0001)$. Switchers also had significantly higher medical costs $(\$ 25,359$ [\$44,998] vs. $\$ 16,886 \quad[\$ 29,281] ; P=0.001)$, mainly due to higher outpatient costs $(\$ 16,800$ [\$24,529] vs. \$12,464 [\$21,313]; $\mathrm{P}<0.001$ ), as well as higher pharmacy costs $(\$ 10,609$ [\$17,863] vs. $\$ 7,006$ [\$13,729]; $\mathrm{P}<0.001)$. The medical and pharmacy costs of discontinuers were comparable to those of nonswitchers (\$17,622 [\$24,957] and \$6,029 [11,433], respectively).

\section{UNADJUSTED ALL-CAUSE HEALTH CARE RESOURCE UTILIZATION AND COSTS DURING THE 1-YEAR FOLLOW-UP PERIOD}

In the 1-year follow-up period, discontinuers and switchers had higher all-cause health care utilization than nonswitchers (Table 3). Switchers had a statistically significantly higher mean (SD) number of ED (0.43 [0.88] vs. 0.41 [1.05]; $P=0.027)$ and outpatient (34.52 [22.25] vs. 25.38 [19.76]; $P<0.001)$ visits per patient per year compared with nonswitchers. Discontinuers had a statistically significantly higher mean (SD) number of ED (0.89 [1.78] vs. 0.41 [1.05]; $\mathrm{P}<0.001)$ and outpatient $(32.76$
[28.39] vs. 25.38 [19.76]; $P=0.001)$ visits per patient per year compared with nonswitchers; however, differences in the frequencies of hospitalizations were not statistically significant.

In the 1-year follow-up period, switchers had a higher all-cause total health care cost compared with nonswitchers, while discontinuers had a lower all-cause total health care cost (Table 3). Switchers had a statistically significantly higher mean (SD) total all-cause health care cost compared with nonswitchers $(\$ 71,280[\$ 25,139]$ vs. $\$ 66,573[\$ 30,803] ; P=0.002)$, which was contributed to by increased medical costs $(\$ 13,897[\$ 15,545]$ vs. $\$ 12,043$ $[\$ 22,405] ; P<0.001)$. The mean total all-cause health care cost for discontinuers ( $\$ 41,179[\$ 35,610] ; \mathrm{P}<0.001 \mathrm{vs}$. nonswitchers) was significantly much lower than that for the other treatment pattern groups due to reduced pharmacy costs (\$22,100 [\$17,093]; $\mathrm{P}<0.001$ vs. nonswitchers). However, discontinuers had the highest medical costs $(\$ 19,079)$ among all 3 treatment pattern groups.

\section{ADJUSTED ALL-CAUSE HEALTH CARE RESOURCE UTILIZATION AND COSTS DURING THE 1-YEAR FOLLOW-UP PERIOD}

Multivariable modeling adjusted for covariates (age, sex, full-time employment status, and Charlson Comorbidity Index) further demonstrated higher health care utilization for switchers and discontinuers compared with nonswitchers (Table 4). Compared with nonswitchers, outpatient visits were more frequent among switchers (adjusted ratio $=1.30[95 \%$ $\mathrm{CI}=1.13-1.49] ; \mathrm{P}<0.001)$ and discontinuers (1.23 [1.10-1.37]; $P<0.001)$. Discontinuers also had more frequent $\mathrm{ED}$ visits than nonswitchers (adjusted ratio $=2.02[95 \% \mathrm{CI}=1.47-2.78] ; \mathrm{P}<0.001)$.

Adjusted analyses of health care costs showed similar trends as the unadjusted analysis (Table 4). 


\section{TABLE 2 Health Care Resource Utilization and Costs Assessed During the 1-Year Baseline Period}

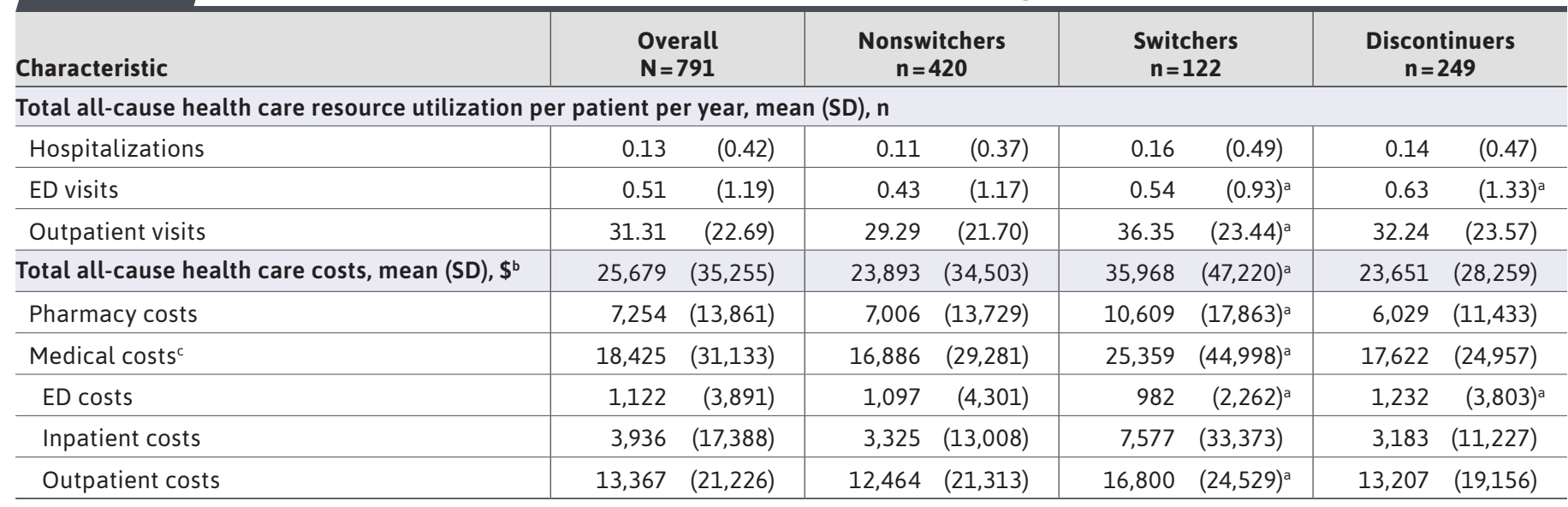

${ }^{a} P<0.05$ vs. nonswitchers.

${ }^{b} T o t a l$ health care costs include medical and outpatient pharmacy costs.

cMedical costs include ED, inpatient, and outpatient costs.

Compared with nonswitchers, switchers had significantly higher outpatient costs (least square means $=\$ 11,146[95 \%$ $\mathrm{CI}=\$ 9,102-\$ 13,649]$ vs. $\$ 7,859 \quad[\$ 7,043-\$ 8,769] ;$ ratio $=1.42$ [1.13-1.79]; $P=0.003)$. Similar to the unadjusted analysis, discontinuers had significantly lower total all-cause health care costs than nonswitchers (least square means $=\$ 39,887$ $[95 \% \mathrm{CI}=\$ 37,549-\$ 42,371]$ vs. $\$ 66,418 \quad[\$ 63,411-\$ 69,568]$; ratio $=0.60[0.56-0.65] ; \mathrm{P}<0.001)$, which was driven by significantly lower pharmacy costs. However, discontinuers still had significantly higher medical costs than nonswitchers (least square means $=\$ 18,027$ [95\% CI $=\$ 15,495-\$ 20,973]$ vs. $\$ 10,677$ [\$9,512-\$11,985]; ratio=1.69 [1.39-2.05]; $\mathrm{P}<0.001$ ), despite controlling for covariates that may contribute to worse clinical state, such as age and comorbidities.

\section{Discussion}

In this retrospective analysis of a U.S. administrative claims database, patients with AS who switched or discontinued biologics were found to have endured a greater economic burden than patients who remained on their index biologic. Overall, $53.1 \%$ of patients remained on their index biologic, $15.4 \%$ switched their biologic, and 31.5\% discontinued their biologic therapy within the 1-year follow-up period. The proportion of switching patterns was similar to what was observed in a previously published retrospective claims analysis using the U.S. Humana database, which was used to evaluate biologic switching patterns across rheumatic indications, including rheumatoid arthritis, psoriasis, psoriatic arthritis, and AS. ${ }^{31}$ Notably, approximately two thirds of discontinuers or switchers in our study were women compared with $<50 \%$ of nonswitchers. This female predominance was also previously reported among TNFi discontinuers, which may be a sign of lower response or higher rate of adverse events with all biologic treatments in women than in men. ${ }^{33,34}$

During the 1-year follow-up period, all-cause health care utilization and cost subcategories demonstrated similar trends regarding switching or discontinuing treatment pattern groups. Patients who switched or discontinued biologics had higher health care resource utilization and medical costs than those who remained on their index biologic. Different trends were observed with switchers and discontinuers with regard to total health care costs. Patients who switched biologics had the highest total health care costs, driven by an increase in pharmacy and medical costs. The mean health care cost for discontinuers was the lowest among the treatment groups due to low pharmacy costs from early discontinuation of therapy. However, discontinuers had the highest mean medical costs, indicating that these patients may still have unstable disease states. Furthermore, discontinuing biologics results in medication wastage from a payer perspective, as initiating a costly drug and not completing treatment causes an excess in medication and imposes an unnecessary economic burden.

Adjusted all-cause health care utilization and costs during the 1-year follow-up period demonstrated similar trends as the unadjusted analysis. Of note, only increases in outpatient costs and outpatient visits were significantly 


\section{TABLE 3}

\section{Unadjusted Health Care Resource Utilization and Costs During 1-Year Follow-up}

\begin{tabular}{|c|c|c|c|}
\hline Unadjusted All-Cause Outcomes & $\begin{array}{c}\text { Nonswitchers } \\
n=420\end{array}$ & $\begin{array}{c}\text { Switchers } \\
n=122\end{array}$ & $\begin{array}{c}\text { Discontinuers } \\
n=249\end{array}$ \\
\hline \multicolumn{4}{|c|}{ Health care utilization, per patient per year, mean (SD), n } \\
\hline Hospitalizations & $0.10 \quad(0.37)$ & $(0.25)$ & $0.15 \quad(0.46)$ \\
\hline ED visits & $0.41 \quad(1.05)$ & $0.43 \quad(0.88)^{\mathrm{a}}$ & $0.89(1.78)^{a}$ \\
\hline Outpatient visits & $25.38 \quad(19.76)$ & $34.52(22.25)^{\mathrm{a}}$ & $32.76(28.39)^{a}$ \\
\hline Total health care costs, mean (SD), \$ & $66,573(30,803)$ & $71,280(25,139)^{a}$ & $41,179(35,610)^{\mathrm{a}}$ \\
\hline Pharmacy costs & $54,530(24,210)$ & $57,384(19,911)$ & $22,100(17,093)^{a}$ \\
\hline Medical costs ${ }^{c}$ & $12,043(22,405)$ & $13,897(15,545)^{\mathrm{a}}$ & $19,079(30,653)^{\mathrm{a}}$ \\
\hline ED costs & $873 \quad(3,914)$ & $983(2,635)^{a}$ & $1,692(4,714)^{a}$ \\
\hline Inpatient costs & $2,541(11,634)$ & $1,361 \quad(6,107)$ & $3,986(21,636)$ \\
\hline Outpatient costs & $8,629(15,182)$ & $11,552(12,269)^{\mathrm{a}}$ & $13,400(17,766)^{\mathrm{a}}$ \\
\hline \multicolumn{4}{|c|}{$\begin{array}{l}{ }^{a} P<0.05 \text { vs. nonswitchers. } \\
{ }^{b} T o t a l \text { health care costs include medical and outpatient pharmacy costs. } \\
\text { cMedical costs include ED, inpatient, and outpatient costs. } \\
E D=\text { emergency department. }\end{array}$} \\
\hline
\end{tabular}

different in switchers versus nonswitchers in the adjusted analysis. Small sample sizes in the switchers group may have precluded the ability to detect significant trends across other health care utilization and costs outcomes in the adjusted analysis. However, adjusting for covariates that may have contributed to a worse clinical state (e.g., age and comorbidities) revealed that discontinuers did have higher medical costs than nonswitchers due to higher outpatient costs from early discontinuation, further supporting that these patients may still have active disease.

Although the reasons for discontinuation or switch were not evaluated in this study, prior studies in patients who discontinued or switched biologics found that the most common reasons were adverse events, lack of treatment effect, or disease progression. ${ }^{35-38}$ Of note, higher disease activity is a predictor of discontinuation $^{35}$ or switch, ${ }^{39}$ as shown by higher Bath Ankylosing Spondylitis Disease
Activity Index and Health Assessment Questionnaire scores, respectively.

In our study, at baseline, switchers had significantly higher health care resource utilization and medical costs compared with nonswitchers, which may suggest that these patients had more complicated disease conditions at baseline. A previous study using a claims database in China reported that patients with AS receiving biologics have the highest direct medical costs compared with those on other conventional therapies. ${ }^{32}$ To account for potential confounding of baseline health status, we adjusted for baseline covariates that may represent a patient's need for health care services as a proxy for health status or predictors of future health care utilization (e.g., age, sex, and comorbidities).

Few studies in the United States have reported on health care utilization and costs of switching or discontinuing biologics among patients with AS; therefore, this study provides valuable insight into the financial implications of switching treatments, which is important for payers to make informed formulary decisions. From a policy perspective, this study informs health care administrators on the costs of switching and/or discontinuing therapies, allowing them to better weigh the option of incurring costs of forcing patients and physicians to switch therapies or potentially saving costs by remaining on the current therapy. Furthermore, these findings provide physicians with essential information on the financial burden of switching, suggesting proper treatment decisions and appropriate treatment selection as a means to alleviate both the clinical and economic burdens of AS.

Given that patients' reasons for switching among TNFis were primarily due to a lack of efficacy or adverse events, ${ }^{35-37}$ more than $40 \%$ of patients with AS treated with TNFis may initiate add-on therapy with NSAIDs, opioids, corticosteroids, conventional synthetic disease-modifying antirheumatic drugs, antidepressants, anxiolytics, sleeping aids, and topical analgesics. ${ }^{30}$ This results in an increase in medication burden and treatment costs; thus, shared decision making between physicians and patients is important to optimize treatment and outcomes. Future studies exploring reasons for switching or discontinuing are warranted, as these may provide a better perspective on selecting more durable treatments.

\section{LIMITATIONS}

Despite having several strengths, due to its nature, this study has a few limitations. There is potential for misclassification of clinical characteristics or events, as all data were dependent on claims information. The validity of the analysis related to switching is only sensitive to the accuracy of the data recorded from the claims database. The measurement error around claims for expensive medication is likely low; however, uncertainty around the cost 


\section{TABLE 4 Adjusted Health Care Resource Utilization and Costs During 1-Year Follow-upa}

\begin{tabular}{|c|c|c|c|c|c|c|c|c|c|c|}
\hline \multirow{2}{*}{$\begin{array}{l}\text { Adjusted All-Cause } \\
\text { Outcomes }^{\text {b }}\end{array}$} & \multicolumn{2}{|c|}{$\begin{array}{c}\text { Nonswitchers } \\
n=420\end{array}$} & \multicolumn{2}{|c|}{$\begin{array}{c}\text { Switchers } \\
n=122\end{array}$} & \multicolumn{2}{|c|}{$\begin{array}{c}\text { Discontinuers } \\
n=249\end{array}$} & \multicolumn{2}{|c|}{$\begin{array}{l}\text { Switchers vs. } \\
\text { nonswitchers }\end{array}$} & \multicolumn{2}{|c|}{$\begin{array}{c}\text { Discontinuers vs. } \\
\text { nonswitchers }\end{array}$} \\
\hline & \multicolumn{6}{|c|}{$\operatorname{LSM}(95 \% \mathrm{CI})$} & \multicolumn{4}{|c|}{ Ratio $(95 \% \mathrm{Cl})$} \\
\hline \multicolumn{11}{|c|}{ Health care resource utilization } \\
\hline Hospitalizations & 0.08 & $(0.06-0.12)$ & 0.06 & $(0.03-0.12)$ & 0.13 & $(0.09-0.19)$ & 0.68 & $(0.30-1.55)$ & 1.55 & $(0.93-2.59)$ \\
\hline ED visits & 0.39 & $(0.32-0.49)$ & 0.43 & $(0.29-0.63)$ & 0.79 & $(0.62-1.01)$ & 1.09 & $(0.70-1.70)$ & 2.02 & $(1.47-2.78)^{c}$ \\
\hline Outpatient visits & 24.88 & $(23.29-26.58)$ & 32.27 & $(28.58-36.43)$ & 30.62 & $(28.12-33.34)$ & 1.30 & $(1.13-1.49)^{c}$ & 1.23 & $(1.10-1.37)^{c}$ \\
\hline \multicolumn{11}{|l|}{ Health care costs, $\$$} \\
\hline Total health care costs & 66,418 & $(63,411-69,568)$ & 70,878 & $(65,025-77,527)$ & 39,887 & $(37,549-42,371)$ & 1.07 & $(0.97-1.18)$ & 0.60 & $(0.56-0.65)^{c}$ \\
\hline Pharmacy costs & 54,626 & $(51,615-57,812)$ & 57,383 & $(51,633-63,772)$ & 21,856 & $(20,300-23,530)$ & 1.05 & $(0.93-1.18)$ & 0.40 & $(0.36-0.44)^{c}$ \\
\hline Medical costs ${ }^{d}$ & 10,677 & $(9,512-11,985)$ & 13,317 & $(10,756-16,486)$ & 18,027 & $(15,495-20,973)$ & 1.25 & $(0.98-1.59)$ & 1.69 & $(1.39-2.05)^{c}$ \\
\hline ED costs & 843 & $(503-1,413)$ & 981 & $(382-2,521)$ & 1,562 & $(786-3,103)$ & 1.16 & $(0.40-3.40)$ & 1.85 & $(0.77-4.47)$ \\
\hline Inpatient costs & 1,838 & $(595-5,678)$ & 1,171 & $(146-9,368)$ & 3,210 & $(748-13,774)$ & 0.64 & $(0.06-7.09)$ & 1.75 & $(0.26-11.53)$ \\
\hline Outpatient costs & 7,859 & $(7,043-8,769)$ & 11,146 & $(9,102-13,649)$ & 12,961 & $(11,224-14,967)$ & 1.42 & $(1.13-1.79)^{c}$ & 1.65 & $(1.37-1.98)^{c}$ \\
\hline
\end{tabular}

${ }^{a}$ Covariates included age, sex, full-time employment (yes or no), and baseline Charlson Comorbidity Index.

${ }^{b}$ All outcomes were derived from a negative binomial distribution with log link functions for models.

c $P<0.05$ vs. nonswitchers.

'Medical costs include ED, inpatient, and outpatient costs.

$E D=$ emergency department; $L S M=$ least squares mean.

of switching may remain. For the medical claims, the data on drugs administered by a medical procedure do not contain information on the number of days of supply. As the data are limited to those patients who have commercial and Medicare supplemental insurance, the current findings may not be generalizable to the general population; furthermore, costs may have been underestimated for patients who received supplemental health care or those who did not have insurance coverage and were not included in the claims database.

Based on the definition of a permissible treatment gap of $>120$ days, patients may be misclassified as discontinuers, and this may bias differences in cost estimates toward null. Our study did not capture data for patients who restarted therapy or their reasons for switch or discontinuation. Additional long-term analyses of real-world data, as well as analyses linking claims to electronic medical records data, are warranted to corroborate these findings, with the goal of identifying treatments with sustained safety and efficacy to alleviate the clinical and economic burden of switching or discontinuing biologic therapies.

\section{Conclusions}

This analysis of U.S. administrative claims data suggests that patients with AS who switch or discontinue biologics within the first year of initiating their biologic have higher health care utilization and higher medical costs than those who remain on their index biologic. For payers, biologic discontinuation may impose economic burden due to medication wastage. These findings reflect current real-world treatment patterns and emphasize the clinical and economic impact of discontinuing or switching biologic therapies in patients with AS.

This analysis may encourage payers to weigh the additional costs associated with switching therapies or potential savings associated with remaining on current therapies during formulary decision making. Moreover, these results suggest a need to identify and appropriately select treatments with sustained safety and efficacy to lessen the clinical and economic burden of discontinuing or switching biologic therapies. 


\section{DISCLOSURES}

This study was sponsored by Novartis Pharmaceuticals (East Hanover, NJ). Yi, Dai, and Park are employed by Novartis. Piao was an employee of KMK Consulting, supporting Novartis at the time of this study; Zheng is an employee of KMK Consulting and works as a consultant for Novartis.

Portions of this work were presented at the 2019 AMCP Managed Care and Specialty Pharmacy Annual Meeting; March 25-28, 2019; San Diego, CA; and AMCP Nexus 2019; October 29-November 1, 2019; National Harbor, MD.

\section{ACKNOWLEDGMENTS}

Support for third-party writing assistance for this manuscript, furnished by Meaghan Paganelli, PhD (Health Interactions), was provided by Novartis Pharmaceuticals.

\section{REFERENCES}

1. Braun J, Sieper J. Ankylosing spondylitis. Lancet. 2007;369(9570):1379-90.

2. Sieper J, van der Heijde D, Landewe R, et al. New criteria for inflammatory back pain in patients with chronic back pain: a real patient exercise by experts from the Assessment of SpondyloArthritis International Society (ASAS). Ann Rheum Dis. 2009;68(6):784-88.

3. Reveille JD. Epidemiology of spondyloarthritis in North America. Am J Med Sci. 2011;341(4):284-86

4. Rudwaleit M, Jurik AG, Hermann KG, et al. Defining active sacroiliitis on magnetic resonance imaging (MRI) for classification of axial spondyloarthritis: a consensual approach by the ASAS/ OMERACT MRI group. Ann Rheum Dis. 2009;68(10):1520-7.

5. van der Linden S, Valkenburg HA, Cats A. Evaluation of diagnostic criteria for ankylosing spondylitis. A proposal for modification of the New York criteria. Arthritis Rheum. 1984;27(4):361-68.
6. Strand V, Rao SA, Shillington AC, Cifaldi MA, McGuire M, Ruderman EM. Prevalence of axial spondyloarthritis in United States rheumatology practices: Assessment of SpondyloArthritis International Society criteria versus rheumatology expert clinical diagnosis. Arthritis Care Res (Hoboken). 2013;65(8):1299-306.

7. Khan MA. Ankylosing spondylitis: introductory comments on its diagnosis and treatment. Ann Rheum Dis. 2002;61 (Suppl 3):iii3-7.

8. Davis JC Jr. Understanding the role of tumor necrosis factor inhibition in ankylosing spondylitis. Semin Arthritis Rheum. 2005;34(4):668-77.

9. Deodhar A, Mittal M, Reilly P, et al. Ankylosing spondylitis diagnosis in U.S. patients with back pain: identifying providers involved and factors associated with rheumatology referral delay. Clin Rheumatol. 2016;35(7):1769-76.

10. Braun J, Sieper J. Therapy of ankylosing spondylitis and other spondyloarthritides: established medical treatment, anti-TNFalpha therapy and other novel approaches. Arthritis Res. 2002;4(5):307-21.

11. Gran JT, Skomsvoll JF. The outcome of ankylosing spondylitis: a study of 100 patients. Br J Rheumatol. 1997;36(7):766-71.

12. Walsh JA, Song X, Kim G, Park Y. Healthcare utilization and direct costs in patients with ankylosing spondylitis using a large U.S. administrative claims database. Rheumatol Ther. 2018;5(2):463-74.

13. Ogdie A, Benjamin Nowell W, Reynolds R, et al. Real-world patient experience on the path to diagnosis of ankylosing spondylitis. Rheumatol Ther. 2019;6(2):255-67.

14. Malinowski KP, Kawalec P. The indirect costs of ankylosing spondylitis: a systematic review and meta-analysis. Expert Rev Pharmacoecon Outcomes Res. 2015;15(2):285-300.

15. Palla I, Trieste L, Tani C, et al. A systematic literature review of the economic impact of ankylosing spondylitis. Clin Exp Rheumatol. 2012;30(4 Suppl 73):S136-41.
16. van der Heijde D, Ramiro S, Landewe R, et al. 2016 update of the ASAS-EULAR management recommendations for axial spondyloarthritis. Ann Rheum Dis. 2017;76(6):978-91.

17. Ward MM, Deodhar A, Gensler LS, et al 2019 Update of the American College of Rheumatology/Spondylitis Association of America/Spondyloarthritis Research and Treatment Network recommendations for the treatment of ankylosing spondylitis and nonradiographic axial spondyloarthritis. Arthritis Care Res (Hoboken). 2019;71(10):1599-613.

18. Maxwell LJ, Zochling J, Boonen A, et al. TNF-alpha inhibitors for ankylosing spondylitis. Cochrane Database Syst Rev. 2015;(4):CD005468.

19. Davis JC Jr, Van Der Heijde D, Braun J, et al. Recombinant human tumor necrosis factor receptor (etanercept) for treating ankylosing spondylitis: a randomized, controlled trial. Arthritis Rheum. 2003;48(11):3230-36.

20. Braun J, Brandt J, Listing J, et al. Treatment of active ankylosing spondylitis with infliximab: a randomised controlled multicentre trial. Lancet. 2002;359(9313):1187-93.

21. Landewe R, Braun J, Deodhar A, et al. Efficacy of certolizumab pegol on signs and symptoms of axial spondyloarthritis including ankylosing spondylitis: 24-week results of a double-blind randomised placebo-controlled phase 3 study. Ann Rheum Dis. 2014;73(1):39-47.

22. Inman RD, Davis JC Jr, Heijde D, et al. Efficacy and safety of golimumab in patients with ankylosing spondylitis: results of a randomized, double-blind, placebo-controlled, phase III trial. Arthritis Rheum. 2008;58(11):3402-12.

23. van der Heijde D, Kivitz A, Schiff MH, et al. Efficacy and safety of adalimumab in patients with ankylosing spondylitis: results of a multicenter, randomized, double-blind, placebo-controlled trial. Arthritis Rheum. 2006;54(7):2136-46. 
24. Baeten D, Baraliakos X, Braun J, et al. Anti-interleukin-17A monoclonal antibody secukinumab in treatment of ankylosing spondylitis: a randomised, doubleblind, placebo-controlled trial. Lancet. 2013;382(9906):1705-13.

25. Deodhar A, Poddubnyy D, PachecoTena C, et al. Efficacy and safety of ixekizumab in the treatment of radiographic axial spondyloarthritis: sixteen-week results from a phase III randomized, double-blind, placebo-controlled trial in patients with prior inadequate response to or intolerance of tumor necrosis factor inhibitors. Arthritis Rheumatol. 2019;71(4):599-611.

26. van der Heijde D, Cheng-Chung Wei J, Dougados $\mathrm{M}$, et al. Ixekizumab, an interleukin-17A antagonist in the treatment of ankylosing spondylitis or radiographic axial spondyloarthritis in patients previously untreated with biological disease-modifying anti-rheumatic drugs (COAST-V): 16 week results of a phase 3 randomised, double-blind, activecontrolled and placebo-controlled trial. Lancet. 2018;392(10163):2441-51.

27. Navarro-Compan V, PlasenciaRodriguez C, de Miguel E, Diaz Del Campo $\mathrm{P}$, Balsa A, Gratacos J. Switching biological disease-modifying antirheumatic drugs in patients with axial spondyloarthritis: results from a systematic literature review. RMD Open. 2017;3(2):e000524.

28. Conti F, Ceccarelli F, Marocchi E, et al. Switching tumour necrosis factor alpha antagonists in patients with ankylosing spondylitis and psoriatic arthritis: an observational study over a 5-year period. Ann Rheum Dis. 2007;66(10):1393-97.
29. Lie E, van der Heijde D, Uhlig T, et al. Effectiveness of switching between TNF inhibitors in ankylosing spondylitis: data from the NOR-DMARD register. Ann Rheum Dis. 2011;70(1):157-63.

30. Walsh JA, Adejoro O, Chastek B, Park Y. Treatment patterns of biologics in U.S. patients with ankylosing spondylitis: descriptive analyses from a claims database. J Comp Eff Res. 2018;7(4):369-80.

31. Howe A, Eyck LT, Dufour R, Shah N, Harrison DJ. Treatment patterns and annual drug costs of biologic therapies across indications from the Humana commercial database. J Manag Care Spec Pharm. 2014;20(12):1236-44. doi:10.18553/ jmcp.2014.20.12.1236

32. Li J, Liu Q, Chen Y, et al. Treatment patterns, complications, and direct medical costs associated with ankylosing spondylitis in Chinese urban patients: a retrospective claims dataset analysis. J Med Econ. 2017;20(1):91-97.

33. Glintborg B, Ostergaard M, Krogh NS, Dreyer L, Kristensen HL, Hetland ML. Predictors of treatment response and drug continuation in 842 patients with ankylosing spondylitis treated with antitumour necrosis factor: results from 8 years' surveillance in the Danish nationwide DANBIO registry. Ann Rheum Dis. 2010;69(11):2002-08.

34. Heiberg MS, Koldingsnes W, Mikkelsen K, et al. The comparative one-year performance of anti-tumor necrosis factor alpha drugs in patients with rheumatoid arthritis, psoriatic arthritis, and ankylosing spondylitis: results from a longitudinal, observational, multicenter study. Arthritis Rheum. 2008;59(2):234-40.
35. Arends S, Brouwer E, van der Veer E, et al. Baseline predictors of response and discontinuation of tumor necrosis factor-alpha blocking therapy in ankylosing spondylitis: a prospective longitudinal observational cohort study. Arthritis Res Ther. 2011;13(3):R94.

36. Bonafede M, Fox KM, Watson C, Princic N, Gandra SR. Treatment patterns in the first year after initiating tumor necrosis factor blockers in real-world settings. Adv Ther. 2012;29(8):664-74.

37. Hyrich KL, Lunt M, Dixon WG, Watson KD, Symmons DP, BSR Biologics Register. Effects of switching between anti-TNF therapies on HAQ response in patients who do not respond to their first anti-TNF drug. Rheumatology (Oxford). 2008;47(7):1000-05.

38. Joshi R, Latremouille-Viau D, Meiselbach MK, Xie J, Park Y, Sunkureddi P. Characterization of patients with ankylosing spondylitis receiving secukinumab and reasons for initiating treatment: a U.S. physician survey and retrospective medical chart review. Drugs Real World Outcomes. 2019;6(1):1-9.

39. Glintborg B, Ostergaard M, Krogh NS, et al. Clinical response, drug survival and predictors thereof in 432 ankylosing spondylitis patients after switching tumour necrosis factor alpha inhibitor therapy: results from the Danish nationwide DANBIO registry. Ann Rheum Dis. 2013;72(7):1149-55 